\title{
Segurança Alimentar e Nutricional e Tecnologias Sociais em Educação Alimentar e Nutricional: notas sobre um projeto de pesquisa e extensão
}

\author{
Lígia Amparo-Santos ${ }^{1,5}$, Micheli Dantas Soares ${ }^{2,5}$, Lilian Miranda Magalhães ${ }^{3,5}$, \\ Amélia Borba Costa Reis ${ }^{4,5}$, Débora Cruz Porcino ${ }^{4,5}$, Michele Oliveira dos Santos ${ }^{4,5}$, \\ Iane Carine Freitas da Silva ${ }^{4,5}$, Jasilaine Andrade Passos ${ }^{4,5}$
}

\begin{abstract}
Este ensaio pretende refletir sobre um projeto de pesquisa e extensão no campo de Tecnologias Sociais em Educação Alimentar e Nutricional com vistas a favorecer a ampliação da garantia da Segurança Alimentar e Nutricional e a promoção da alimentação saudável de comunidades populares. Partindo da compreensão que o empreendimento concilia marcos referenciais da educação a uma complexa trama de dimensões que conforma o fenômeno da alimentação humana, discutiremos, inicialmente, o cenário no qual o debate sobre a emergência de novas configurações de Educação Alimentar e Nutricional se desenha no campo das políticas públicas, culminando com a proposição de um marco referencial para o referido campo. Em seguida, serão apresentados os fundamentos teóricos e metodológicos que animaram a proposição do projeto. Neste quesito, o enfoque da discussão centra-se nos marcos referenciais da educação e das ciências sociais em saúde em diálogo com as ciências da nutrição. Posteriormente, descreve-se o contexto do estudo e a experiência de Educação Alimentar e Nutricional desenvolvida, ao lado de uma análise dos alcances e limites à luz dos princípios metodológicos propostos e efetivamente concretizados.
\end{abstract}

Palavras-chave: Educação Alimentar e Nutricional, Paulo Freire, Segurança Alimentar e Nutricional, Tecnologias Sociais.

\section{Food and Nutrition Security and Social Technologies in Nutrition Education: a research and extension project}

This essay aims to reflect on a research project in the field of social technologies in Food and Nutrition Education with a view to encourage of guaranteeing Food and Nutrition Security as well as promoting healthy eating in lowincome communities. Based on the understanding that the project combines education with a complex plot of the phenomenon that shapes the human diet, we discuss initially the scenario in which the debate on the emergence of new configurations of Food and Nutrition Education is outlined in the field of public policies, culminating with the proposition of a framework to the field. Then, we will present the theoretical and methodological proposition that animated the project. In this regard, the discussion focuses on the milestones of education and social sciences in health dialogue with the sciences of nutrition. Subsequently, we describe the context of the study and experience of Food and Nutrition Education developed alongside an analysis of the scope and limits considering the methodological principles proposed and implemented effectively.

Key-Words: Food and Nutrition Education, Paulo Freire, Food and Nutrition Security, Social Technologies.

\footnotetext{
${ }^{1}$ Profa Adjunta, Escola de Nutrição, Universidade Federal da Bahia (UFBA). Coordenadora do Núcleo de Estudos e Pesquisas em Alimentação e Cultura (NEPAC). Correspondência: Av. Araújo Pinho, 32, Canela, Salvador, BA. CEP 40110-150. E-mail: amparo@ufba.br.

${ }^{2}$ Prof ${ }^{a}$ Adjunta do Centro de Ciências da Saúde, Universidade Federal do Recôncavo da Bahia (UFRB).

${ }^{3}$ Mestre em Alimentos, Nutrição e Saúde, Escola de Nutrição. Nutricionista e Professora Substituta da Escola de Nutrição (UFBA).

${ }^{4}$ Nutricionista, Mestranda do Programa de Pós-graduação em Alimentos, Nutrição e Saúde, Escola de Nutrição (UFBA).

${ }^{5}$ Membro do NEPAC, Escola de Nutrição (UFBA).
} 


\section{CONSIDERAÇÕES INICIAIS}

Este texto apresenta reflexões acerca de um projeto de pesquisa e extensão que visa à construção de Tecnologias Sociais (TS) em Educação Alimentar e Nutricional (EAN), ao tempo que expressa os princípios teórico-metodológicos a partir dos quais se desdobraram as experiências educativas em alimentação e nutrição no escopo deste estudo. A proposta de EAN aliada à construção de TS teve por objetivo favorecer a ampliação da Segurança Alimentar e Nutricional (SAN) e a promoção da alimentação saudável das comunidades envolvidas.

A proposição deste projeto vem ao encontro de demandas crescentes em torno de ações e programas de EAN que ultrapassem os padrões vigentes das práticas neste campo, de caráter tradicional e comportamentalista, bem como corresponde à necessidade, também premente, de um tratamento reflexivo das questões conceituais, metodológicas e operacionais que sustentam as experiências de EAN.

Partindo da compreensão que o empreendimento concilia marcos referenciais da educação a uma complexa trama de dimensões que conforma o fenômeno da alimentação humana, discutiremos, inicialmente, o cenário no qual o debate sobre a emergência de novas configurações de EAN se desenha no campo das políticas públicas, culminando com a proposição de um marco referencial para o referido campo. Em seguida, serão apresentados os fundamentos teóricos e metodológicos que animaram a proposição do projeto. Neste quesito, o enfoque da discussão centra-se nos marcos referenciais da educação e das ciências sociais em saúde em diálogo com as ciências da nutrição. Posteriormente, descrevese o contexto do estudo e a experiência de EAN desenvolvida, ao lado de uma análise dos alcances e limites à luz dos princípios metodológicos propostos e efetivamente concretizados.

\section{PANORAMA DO CAMPO DA EDUCAÇAO ALIMENTAR E NUTRICIONAL (EAN)}

A EAN constitui uma estratégia que vem de modo crescente sendo preconizada pelas políticas públicas em alimentação e nutrição, na medida em que é considerada como um importante instrumento para promoção de práticas alimentares saudáveis. No contexto brasileiro, a última década passou a albergar, sob o eixo articulador da garantia da SAN, dimensões mais ampliadas, destacando-se a necessidade de superar a visão dietista e contemplar interfaces com questões econômicas, políticas, ambientais, culturais e antropológicas da alimentação [1].

A importância da EAN no campo da saúde, alimentação e nutrição, bem como o seu percurso histórico têm sido discutida por diferentes autores [2-5]. Santos [5] destaca que entre as décadas de 1940 e 1960 as ações de EAN eram direcionadas aos indivíduos considerando-os, em alguma medida, culpabilizados pela sua ignorância. Posteriormente, o arcabouço teórico que balizou as ações no campo detinha-se no reconhecimento da organização social capitalista como responsável pelos problemas alimentares (1970-90). Atualmente, os sujeitos são reconhecidos como titulares de direitos e convocados a ampliar o seu poder de escolha e decisão (1990-2010). Observou-se, a partir de então, a relevância assumida pela EAN no âmbito das políticas públicas em alimentação e nutrição.

A questão da promoção das práticas alimentares saudáveis passou a constar nos programas oficiais brasileiros, a exemplo da Política Nacional de Alimentação e Nutrição (PNAN) [6], implantada no final da década de 1990, na qual se observa o fomento às ações em alimentação e nutrição, incluindo a perspectiva de acesso universal aos alimentos. Abordagens semelhantes constam também na Estratégia Fome Zero, lançada em 2001, que contempla a importância da EAN associada à educação para o consumo [7] e na Política Nacional de Promoção da Saúde, lançada em 2006, que prioriza as ações de Promoção da Alimentação Saudável, na qual a EAN é destacada como estratégica no seu campo de atuação ${ }^{[8]}$. O mesmo se observa na Política Nacional de Segurança Alimentar e Nutricional (PNSAN), sancionada em 2010, com objetivo de assegurar o Direito Humano à Alimentação Adequada (DHAA), tendo como base práticas alimentares promotoras de saúde [9].

Neste cenário de políticas que alçam a EAN como estratégica à promoção de práticas alimentares saudáveis, à consecução da SAN e a realização do DHAA, resultou, também, em um conjunto de eventos que visaram ampliar o debate sobre o tema, a exemplo do 1 을 Encontro Nacional de Educação Alimentar e Nutricional - Discutindo Diretrizes, realizado em 2011, promovido pelo Ministério do Desenvolvimento Social em parceria com os Ministérios da Educação e da Saúde. Este encontro juntamente com a atividade Integradora sobre EAN realizada durante a IV Conferência Nacional de Segurança Alimentar e 
Nutricional em 2011, a Oficina de Trabalho PréCongresso do World Nutrition em 2012 e outros documentos provocaram uma mobilização a favor da construção coletiva, mediante consulta pública, de um Marco de Referência de EAN para as Políticas Públicas. A construção deste Marco decorreu da iniciativa do Ministério do Desenvolvimento Social e Combate à Fome (MDS), com apoio de outros parceiros - Ministério da Saúde (MS), Ministério da Educação (MEC), Associação Brasileira de Nutrição (ASBRAN), Conselho Federal de Nutrição (CFN), Observatório de Políticas Públicas de SAN da Universidade de Brasilia (OPSAN/UnB), dentre outros.

O Marco de Referência destaca a crescente importância da EAN para enfrentar os novos desafios no campo da saúde, da alimentação e nutrição, da garantia da SAN e do DHAA. Propõe que as práticas desenvolvidas assumam uma perspectiva da educação popular, cunhada no pensamento de Paulo Freire, com ênfase na dialogicidade e na autonomia do sujeito, contrapondo os métodos tradicionais baseados nas técnicas expositivas. Entretanto, enfatiza o incipiente arcabouço teórico, metodológico e operacional no campo, incentivando, assim, o desenvolvimento de ações/práticas respaldadas por princípios norteadores, tais como o resgate e valorização da cultura alimentar $\mathrm{e}$ dos diversos saberes, a participação ativa dos sujeitos visando promoção da autonomia e autodeterminação, práticas educativas problematizadoras e geradoras de autonomia, o desenvolvimento de ações intersetoriais e que abriguem atividades de planejamento, avaliação e monitoramento. Destarte, reconhece que o campo da EAN carece de estudos acerca dos fundamentos teórico-metodológicos e operacionais que visem à construção de estratégias inovadoras ${ }^{[10]}$.

Estudos demonstram que os discursos e recomendações não correspondem às práticas desenvolvidas, a exemplo dos achados de AlzateYepes [11], cujo estudo, procurando identificar os referenciais pedagógicos em 45 experiências de intervenções educativas em saúde e nutrição, concluiu que a maioria destas experiências não explicitava os referenciais pedagógicos utilizados. Dentre aquelas que explicitavam, percebeu-se que algumas apresentavam incoerências no desenvolvimento da estratégia educativa, nas quais a teoria informada não correspondia à prática proposta. Constatou, ainda, a coexistência de pedagogias críticas, com base em modelos cognitivos de aprendizagem psicossocial e contextual, com o oposto, tradicional, de base comportamental.

Nesta esteira, constata-se que apesar dos avanços nas discussões no campo da EAN e da SAN, reconhece-se que há um hiato entre as formulações das políticas e as práticas desenvolvidas no campo da EAN e da SAN. Deste modo, o propósito do projeto foi desenvolver experiências baseadas nos princípios norteadores que estão presentes nas produções acadêmico-científicas e nos documentos referências que orientam tais ações.

\section{SOBRE PRINCÍPIOS TEÓRICO- EPISTEMOLÓGICOS ADOTADOS}

Para o desenvolvimento do projeto em questão, dois eixos centrais foram adotados: o conceito de TS para EAN e a adoção da perspectiva crítica das ciências da nutrição. No que se refere ao primeiro, o conceito de TS para EAN, destaca-se a relevância da construção coletiva e não transferência de tecnologias, assim como a base na sócio-sustentabilidade ambiental, inclusão social e direito às diferenças, sendo que tais aspectos coadunam com os estabelecidos também na área de alimentação e nutrição.

A expressão TS ganhou força em meados da década de 1990 e foi bastante influenciada pelo movimento das Tecnologias Apropriadas (TA) - sendo as duas pertencentes à mesma vertente - entretanto, se diferenciam acima de tudo pelo fato de no campo de TS a comunidade não ser considerada como mera receptora da tecnologia, e sim, atores diretos na construção e desenvolvimento desta. A Tecnologia Social aponta para uma concepção da simples transferência de tecnologias, incluindo em sua prática um processo democrático, participativo e com ênfase na dimensão pedagógica ${ }^{[12]}$.

Deste modo, o conceito de TS visa o desenvolvimento de metodologias em interação com a comunidade a fim de representar efetivas soluções para possibilitar a autonomia do sujeito, a inclusão social e melhoria da qualidade de vida [13,14]. Cabe salientar que, para Bonilha \& Sachuk [15], a Tecnologia Social é um instrumento que engloba o conhecimento técnicocientífico e permite aos sujeitos exclú́dos da sociedade uma ressocialização e transformação da sua própria identidade. Para os autores, Teconologia Social é uma proposta participativa de construção do conhecimento, de fazer ciência e tecnologia para o desenvolvimento e 
realização do ser humano e de seus interesses coletivos, ou seja, podendo favorecer a redução das desigualdades sociais. Rodrigues \& Barbieri [13] ainda enfatizam que a Tecnologia Social dedica-se ao processo de produção, contrapondo a tecnologia convencional, cuja ênfase é no produto.

No que se refere à adoção da perspectiva crítica das ciências da nutrição, este princípio é aqui entendido como uma construção histórica e cultural e não como uma produção fruto da neutralidade científica, portanto, restando aos educadores apenas "transmitir" as verdades científicas advindas das investigações do campo. Santos ${ }^{[16]}$ ressalta que a ciência da nutrição, tal como é concebida hoje, tem a sua origem no século XIX, no período da Revolução Industrial, cujo interesse científico era medir os efeitos da caloria na ingestão humana, com ênfase na combinação da dieta mínima com o máximo de produção de energia. Época na qual se estabeleceu a metáfora do corpo enquanto máquina produtiva sujeito às leis da termodinâmica que demandava energia. Fruto deste legado secular, a ideia de mensuração com precisão e certeza da eficiência da dieta no corpo humano, a partir da ação dos nutrientes, passou a compor um novo discurso sobre a alimentação, baseado na cientificidade hegemônica.

Vale ainda ressaltar que a adoção de uma perspectiva crítica da ciência da nutrição reflete a própria história de criticidade da ciência. Trata-se de um movimento situado a partir do século $\mathrm{XX}$, quando abordagens fenomenológicas, psicanalistas, feministas, dentre outras têm estabelecido um outro estatuto para as subjetividades no campo científico. Neste contexto, as dimensões subjetivas que envolvem as práticas alimentares tomam visibilidade no contexto atual e temas como a comensalidade, cultura alimentar, dentre outros, são colocados em tela.

Nesta esteira, decorre outro princípio que se refere ao reconhecimento da comensalidade como objeto de saberes. O comer como um ato ao mesmo tempo biológico e cultural, o seu caráter socializador e marcador de identidades contrapõe a concepção de uma possível "dieta universal", de massa. Assim, prioriza-se a relação dos sujeitos com o comer e a comida sob a perspectiva histórica, social, econômica e cultural, estabelecida também na relação entre os sujeitos e a natureza e nos encontros intersubjetivos. Reconhece-se, ainda, o resgate do sabor e do prazer em comer como fundamentais para práticas alimentares adequadas e saudáveis. Tais premissas revelam o reconhecimento da complexidade que o fenômeno da alimentação humana pressupõe, as quais têm orientado diversos trabalhos acadêmico-científicos em alimentação e nutrição nesta direção, bem como marcando presença nos documentos referenciais das políticas públicas de alimentação e nutrição ${ }^{[6,17,18]}$.

Cabe salientar que o reconhecimento de que os "fatores" sociais, psicológicos e culturais integram o fenômeno do comer, do alimentar e do nutrir não representa algo necessariamente recente. Todavia, a porosidade com que estas expressões se entrelaçam no cotidiano dos sujeitos, faz revisitar tais questões propondo reflexões que tendem a romper as barreiras dos "fatores" para construir saberes cuja interdisciplinaridade e a dialogicidade se façam presentes, buscando, ainda, superar o tratamento do tema aprisionando-o às tradições disciplinares de modo circunscrito [19], firmadas em dicotomias binárias clássicas, tais como biológico e social, natureza e cultura, dentre outras.

O que mais interessa neste processo de alargamento das formas de ver e pensar a tríade do comer, alimentar e nutrir é como elas dialogam com as dimensões forjadas pela biomedicina, eixo central da ciência da nutrição desde o seu nascimento. Em outras palavras, como promover mudanças nas práticas alimentares dos sujeitos sob a ótica do saudável e, ao mesmo tempo, respeitar os seus hábitos alimentares, suas tradições e cultura? Esta questão, um dilema talvez, que percorre as políticas e as práticas, irá encontrar na EAN um nó górdio e cabe desenvolver profundas reflexões sobre o tema [20].

Cabe destacar, por exemplo, os dilemas na promoção da alimentação saudável. De um lado, não há um consenso científico sobre alimentação saudável e, de outro, as orientações nutricionais são amplamente disseminadas, ao mesmo tempo que são contraditórias face a velocidade de produção de conhecimento [21], reconhece-se a necessidade de um entendimento mais plural atravessando a concepção de alimentação saudável. Considera, portanto, que esta é uma concepção (ou concepções) a ser trabalhada contextualmente junto aos grupos ou comunidades, promovendo a interação de saberes, tais como os populares e científicos. 


\section{QUANTO AOS PRINCÍPIOS METODOLÓGICOS ADOTADOS}

A proposta educativa inspirara-se no metódo de alfabetização de Paulo Freire [22] constituindo-se em fases de exploração do universo alimentar dos participantes, elegendo temas geradores para a construção da proposta metodológica - objetivos e conteúdos de alimentação e nutrição de forma compartilhada. Ainda está pautada na aprendizagem significativa de David Ausubel [23], o qual considera que a aprendizagem somente é significativa quando o sujeito consegue relacionar significativamente a nova informação a ser aprendida com os conhecimentos prévios existentes na sua rede cognitiva.

Assim, o recurso do diálogo como elemento fundante da atividade educativa é considerado central não só para a construção coletiva dos princípios, como ainda um dos mais relevantes, ao considerá-lo como um pressuposto ontológico da existência humana, condição essencial para tal e o fundamento do encontro dos sujeitos [5].

Destaca-se ainda que o processo de ensinoaprendizagem das ciências da nutrição e da concepção de alimentação saudável a ser desenvolvido não utiliza como prerrogativa a memorização de regras de uma ciência pronta e prescritiva e, sim, a compreensão conceitual e crítica dos conhecimentos trabalhados em uma perspectiva propositiva. Propõe-se ainda que neste processo dialógico prevaleça a interação entre os saberes científicos, populares e artísticos, dentre outros, na qual as diferentes modalidades de conhecimentos sejam respeitadas e compartilhadas na busca da valorização da memória e fortalecimento da identidade das comunidades.

Ademais, a proposta adota a problematização e a valorização do pensamento divergente que consiste na exploração das possibilidades de respostas para um problema e não em uma única solução, prática comum na abordagem prescritiva, exigindo, assim, o exercício da criticidade e da criatividade.

Mais dois aspectos foram centrais neste princípio: os processos de ensino-aprendizagem descentrados nos conhecimentos e nos aspectos comportamentais, mas também nos atitudinais, afetivos e sensoriais e o uso da arte como instrumento educativo - produções cinematográficas, fotográficas, literárias, dentre outras formas de expressão.
Considera-se que a aprendizagem do comer envolve não apenas a racionalidade instrumental, mas também os múltiplos sentidos, ou seja, envolve o aprendizado das sensibilidades. Assim, tornou-se oportuno apropriar-se das possibilidades de aprendizagem a partir do conhecimento artístico. Trata-se também da educação dos sentidos, valorizando a imaginação, a intuição e a criatividade.

\section{CONTEXTUALIZAÇÃO DO ESTUDO E DESCRIÇÃO DA EXPERIÊNCIA}

O estudo intitula-se "Segurança Alimentar e Nutricional: Construindo Tecnologias Sociais em Educação Alimentar e Nutricional em dois bairros populares na Cidade de Salvador e Santo Antônio de Jesus-Bahia", financiado pela Fundação de Amparo à Pesquisa do Estado da Bahia (FAPESB-BA). O objetivo do projeto foi desenvolver e avaliar estratégias de EAN com base nos princípios teóricometodológicos construídos em uma perspectiva "inovadora" e no conceito de TS em comunidades periféricas urbanas, com vistas a contribuir para promoção da alimentação adequada e saudável, da SAN e do reconhecimento da titularidade do DHAA.

O projeto está subdividido em três etapas: construção, realização e avaliação das TS em EAN em grupos sociais das comunidades estudadas, assumindo como pressuposto que se trata de um processo em fluxo, não se configurando como sequência linear de etapas. Cabe ainda destacar que estas etapas não foram estanques, elas intercruzam, além de serem sempre permeadas pelos processos de reflexão e reformulação. Três grupos/cenários prioritários nessas comunidades foram eleitos para o desenvolvimento do estudo, a saber: Agentes Comunitários de Saúde, beneficiários do Programa Bolsa Família, comunidade escolar do ensino público básico.

A escolha destes grupos/cenários se deu por representarem sujeitos para quem, prioritariamente, se dirigem as ações de EAN desenvolvidas pelos principais Ministérios que desenvolvem políticas públicas no campo da alimentação e nutrição, MS, MDS e MEC/Fundo Nacional de Desenvolvimento da Educação (FNDE), respectivamente, respeitando a agenda da política pública brasileira. Assim, articulamse as áreas e equipamentos públicos de saúde, trabalho, assistência social e educação, dentre outros. Pelo fato das ações serem desenvolvidas na mesma comunidade, 
objetiva-se que os grupos - profissionais, comunidades e a equipe da universidade - estabeleçam interações.

Assim, trata-se de um estudo de natureza qualitativa, exploratório-descritivo, baseando-se em três perspectivas teórico-metodológicas: a pesquisa de intervenção [24], os estudos etnográficos [25] e referências da pesquisa avaliativa por triangulação de métodos [26].

Ressalta-se que a pesquisa de intervenção, uma tendência de pesquisa participativa, ao mesmo tempo que promove transformações no espaço social, obtém dados do processo subjacente a ela, ao ser desenvolvida no ambiente natural das ações sociais [24]. Já a adoção da pesquisa avaliativa se pauta pelo fato de que, além do estudo buscar compreender e interpretar os processos de ensino-aprendizagem provocados pelas estratégias de EAN desenvolvidas, pretende-se avaliar a pertinência e os efeitos da intervenção. Parte-se então da concepção de avaliação como uma prática social e ainda como parte constitutiva do processo de formulação e implementação das estratégias educativas de EAN.

Para tal, utilizou-se da técnica de observação participante, desenvolvida durante todo o projeto desde a sua concepção até a avaliação, cujos dados obtidos foram registrados em diários de campo no decorrer da atividade, como ainda foram feitas gravações das reuniões do grupo, com o objetivo de se obter material empírico subsidiário às reflexões e avaliações do grupo. As interações durante as atividades educativas em sala de aula e nos demais espaços de aprendizagem também foram locais de pesquisa.

Neste artigo focar-se-á nas experiências desenvolvidas na cidade de Salvador-Bahia com grupos/cenários dos Agentes Comunitários de Saúde e da Escola Municipal do bairro em estudo. As questões que mobilizam a reflexão são: em que medida os princípios teórico-metodológicos construídos corresponde às diretrizes apontadas pelo campo científico e pelas formulações das políticas públicas; e em que medida as experiências desenvolvidas correspondem aos princípios delineados para o estudo. Trata-se, deste modo, de uma descrição e reflexão sobre estes processos.

\section{A EXPERIÊNCIA DE FORMAÇÃO EM ALIMENTAÇÃO E NUTRIÇÃO JUNTO AOS AGENTES COMUNITÁRIOS DE SAÚDE (ACS)}

A primeira etapa do projeto ocorreu de forma mais sistemática no período compreendido entre março e dezembro de 2011, quando a inserção em campo esteve associada a atividades vinculadas ao Projeto Nacional de Reorientação da Formação Profissional em Saúde (Pró-Saúde), em que o curso de Nutrição está integrado ao Pró-Saúde II. Neste período, a equipe de pesquisadores da Universidade Federal da Bahia (UFBA) composta por professores doutores, mestres, mestrandas e graduandos do curso de Nutrição, do Núcleo de Estudos e Pesquisas em Alimentação e Cultura (NEPAC) e do Programa de Educação Tutorial da Escola de Nutrição/UFBA (PETNUT), composto por estudantes bolsistas da graduação em nutrição em parceria com a equipe do Distrito Sanitário do Subúrbio Ferroviário de Salvador, realizou um levantamento da situação de SAN da comunidade.

Cabe destacar que a equipe manteve-se, durante todo o processo de realização da experiência investigativa, em processo de formação, elegendo os temas a serem trabalhados paralelamente ao desenvolvimento da proposta educativa, mediante sua demanda. A reflexividade e registro da experiência por parte de todos os sujeitos envolvidos foi um aspecto fundamental, considerando o que Martins [27] denominaria de relação intersubjetiva, na qual a relação entre sujeito e objeto propicia tanto o desvelamento do objeto como o desvelamento do sujeito. O referido autor ainda destaca a importância do reconhecimento da imprevisibilidade presente nesta relação já que “tanto o 'outro', que foi tomado como objeto, como o pesquisador, estiveram submetidos a uma situação de 'alteração', vindo a se influenciar mutuamente"(p. 92).

Partindo dos princípios eleitos para o desenvolvimento do projeto, a segunda fase do trabalho envolveu a negociação com os Agentes Comunitários de Saúde (ACS) do Distrito Sanitário. Assim, a elaboração da proposta educativa iniciou-se com um período de pactuação com a gerência do Distrito Sanitário do Subúrbio Ferroviário de Salvador e os ACS alocados nesse Distrito, o qual foi caracterizado pela apresentação do projeto, seus objetivos e propósitos e uma discussão sobre como melhor desenvolvê-lo, incluindo ainda a discussão sobre relações estabelecidas entre a universidade e a comunidade, os desafios, limites e possibilidades da consecução de atividades de pesquisa e extensão. Foi possível obter consensos em torno da proposta e a aceitação da realização desse projeto. 
Em seguida, ocorreu a fase de preparação da equipe do NEPAC e membros do PETNUT da Escola de Nutrição/UFBA, no período de abril e julho de 2012, com a realização de oficinas em que foram discutidos os temas referentes ao estudo e o desenho metodológico a partir dos princípios teóricometodológicos que nortearam a intervenção, denominada de "Fase de Formação em Alimentação e Nutrição".

Esta formação foi dividida em três subfases: A exploratória, a da formação em alimentação e nutrição propriamente dita e a da avaliação. A subfase exploratória teve como objetivo refletir coletivamente (pesquisadores e ACS) sobre aspectos que subsidiassem o processo de formação tais como o lugar do tema alimentação e nutrição na construção dos sujeitos, na formação profissional e atuação dos ACS. Ou seja, refletiu-se quanto à relação dos sujeitos com o comer e o nutrir, assim como contextualizar as práticas alimentares nas comunidades do bairro relacionando com o contexto global; e sobre o lugar que a alimentação e nutrição ocupa na formação e atuação dos ACS. Objetivou ainda construir junto aos participantes os objetivos e temas prioritários para a formação em EAN propriamente dita.

Dentre estas atividades desenvolvidas da subfase exploratória, destaca-se a denominada "Sob o fio da memória", na qual cada participante foi estimulado a construir sua trajetória alimentar ao longo da vida, marcando os eventos mais significativos, seguidos da discussão em pequenos grupos, identificando diferenças e semelhanças nas trajetórias alimentares e, posteriormente, a apresentação dos produtos e discussão ampliada sobre as práticas alimentares: conceitos, contextos e sentidos.

A partir desta atividade, os participantes tiveram a possibilidade de reconstruir as suas trajetórias de permanências e mudanças das práticas alimentares com memórias e lembranças, entrelaçando as racionalidades e os afetos que conferiam sentidos às suas práticas. As práticas alimentares foram contextualizadas no espaço e no tempo, gerando elementos para compreender as transformações, mas também os olhares sobre o comer. Discutiram-se as mudanças na própria conceituação do que seria uma alimentação saudável e o estreitamento da relação alimentação e saúde. Temas como produção local de alimentos, o processo de industrialização, alimento enquanto mercadoria, alimentação e religião, os discursos midiáticos, publicitários e científicos, os programas de suplementação alimentar, dentre inúmeros outros, emergiram e conduziram à questão do que, afinal, seria comer bem e a relação com o comer saudável. A reflexão residiu em torno do como promover uma alimentação saudável e ao mesmo tempo respeitar a cultura alimentar do local.

Tal reflexão foi mobilizadora para a atividade intitulada "Mas afinal, o que é comer, alimentar e nutrir?" a partir de uma tempestade de ideias sobre o que os participantes pensam sobre estes conceitos seguindo para a reflexão sobre as questões: "mas afinal, a minha alimentação é saudável?", "Mas o que seria o saudável?" e "Como eu construo a alimentação saudável no cotidiano?”. A mediação da discussão teve o objetivo de ampliar os conceitos a partir da sua problematização, assim como evidenciar a sua complexidade, indicando ainda os limites da ciência em ofertar respostas simples a fenômenos desta natureza. O propósito foi convidá-los a buscar respostas coletivamente, uma vez que o entrelace das histórias alimentares construídas indicou o papel da construção social do comer.

Ainda nesta subfase, outras atividades focaram na identidade do agente comunitário e seus desafios de atuação, como ainda o lugar da promoção da alimentação saudável nas suas atividades cotidianas. Dentre os desafios apontados, destacam-se: problemas de saúde relacionados à questão da Insegurança Alimentar e Nutricional de um conjunto de famílias; os limites da atuação dos ACS no que tange a esta temática, no que diz respeito aos conhecimentos e métodos educativos; abordagem das famílias nestas situações; papel e ações dos mesmos diante de familias carentes sem acesso a alimentação adequada. Por fim, foram discutidos aspectos no que tange aos objetivos e temas prioritários a serem abordados na subfase seguinte, a da formação em Alimentação e Nutrição, além da avaliação da fase exploratória.

Esta aproximação da realidade dos ACS e da comunidade onde moram e atuam, possibilitou reflexões que serviram de base para o desenho de uma proposta de formação que levasse em conta o contexto sociocultural destes sujeitos. Inspirando-se no "método" de alfabetização de Paulo Freire, considerouse a subfase exploratória como o momento de pesquisa do universo do vocábulo alimentar da comunidade, seguida da definição de temas/palavras geradores. 
Freire aponta que o uso de temas/palavras geradores serve ao processo de codificaçãodescodificação e problematização da situação na qual os atores sociais estão imersos, é uma possibilidade de investigar o pensar dos homens referindo-se à sua realidade, bem como de investigar sua atuação neste contexto [28].

A estratégia adotada para a discussão foi a eleição de um tema gerador em referência às palavras geradoras propostas por Paulo Freire. O autor utiliza um vocábulo como tema principal para o processo de alfabetização, de acordo com sua riqueza semântica, sintática e fonética [22]. Deste modo, elegeu-se o feijão como tema gerador, por considerar seu valor cultural e ao mesmo tempo nutricional na dieta dos brasileiros e da comunidade em estudo.

Considerou-se ainda a sua economia, variedades nos seus tipos e modos de preparo, uma versatilidade que atende ao paladar e à construção identitária do povo brasileiro. A partir da eleição desta palavra, o processo educativo prosseguiu com a elaboração de pequenas frases e textos. Como todo texto também está inserido em um contexto, a discussão sobre as ideias que essas palavras representam favorecem o desenvolvimento do exercício do senso crítico e político do sujeito.

No que se refere à subfase de formação em alimentação e nutrição em si, seu objetivo foi ampliar os conhecimentos que cercam a alimentação e nutrição de modo a qualificar a prática educativa dos ACS na direção da ampliação da SAN e da promoção da alimentação saudável e da saúde em suas áreas de trabalho. A experiência ocorreu em três dias consecutivos somando uma carga horária de 24 horas, com um desenho metodológico que permitiu a interligação entre as atividades realizadas.

Centrou-se em dois grandes eixos, o primeiro relacionado à pergunta "o que preciso saber?" com as temáticas: "alimentação saudável: comer, alimentar e nutrir", trabalhando a construção de conceitos que cercam o tema comer, alimentar e nutrir; a comensalidade no espaço familiar com a referência do "saudável", no qual se buscou abordar a relação do enfoque na família com as fases do curso/ciclo da vida; e a alimentação saudável nas situações patológicas: hipertensão, diabetes e obesidade, dislipidemia, eleitas como prioritárias pelos ACS para serem trabalhadas na formação, assim como alimentação saudável e as situações de Insegurança Alimentar e Nutricional.

O segundo eixo teve ênfase na questão "o que fazer?", trabalhando temas como a "promoção da alimentação saudável" no qual abordou a discussão sobre as estratégias educativas nas práticas dos ACS; e a construção de um possível plano de ação, do qual emergiu o projeto "Conversando sobre Comida", como proposta de continuidade do projeto na comunidade, e que consiste em partilhar saberes e práticas alimentares por meio de rodas de conversas em diferentes espaços - praças, igrejas, dentre outros com moradores do bairro, mediadas pela equipe do NEPAC e pelos ACS.

A discussão da formação em alimentação e nutrição partiu da produção e comercialização do feijão, percorrendo conhecimentos históricos, políticos e econômicos, até o consumo demarcando as diferentes maneiras de preparar e consumir o feijão no universo brasileiro e no bairro em questão, chegando até o estudo do seu valor nutricional. Permeando todo esse processo, estavam as discussões sobre gosto e prazer que envolvem o ato de comer, aceitando este como um ato cultural e seu papel socializador, além do estudo das patologias proporcionadas por excesso ou carência do consumo de nutrientes presentes no feijão e seus diferentes modos de preparo. Houve também a intenção de inverter o modo de pensar a nutrição imposta no universo acadêmico que parte dos nutrientes até chegar ao alimento e a complexidade que envolve o ato de comer.

No que tange à avaliação, esta consiste em quatro momentos diferentes: imediatamente ao final da formação e com três, seis e nove meses após sua finalização. A avaliação ao final da formação foi denominada "O que brotou em mim?", que, a partir da experiência do cultivo do feijão em algodão umedecido que os participantes foram estimulados a desenvolver ao início da formação emergiram as narrativas sobre a experiência formativa. Este exercício permitiu trabalhar noções de cuidado, humanização, bem como conhecer mudança na percepção sobre o tema alimentação e nutrição do primeiro ao último dia de formação. Destas narrativas emergiram aspectos como a contextualização dos temas trabalhados na formação dentro da realidade local, a relação de confiança e o estabelecimento de relações mais "horizontais" entre os mediadores da formação (equipe do NEPAC) e os ACS com uma abordagem participativa, a valorização do 
conhecimento prévio e das experiências vivenciadas pelos sujeitos.

\section{PROJETO DIA DE FEIRA: O TEMA ALIMENTAÇÃO E NUTRIÇÃO NA ESCOLA}

O Dia de Feira constitui-se em um projeto interdisciplinar desenvolvido em uma escola municipal do ensino fundamental de Salvador-Bahia. A experiência aqui posta corresponde ao período ocorrido de julho a dezembro de 2012. Foi produto de uma construção participativa que envolveu estudantes; professores de disciplinas distintas; a coordenadora pedagógica; a gestora escolar; bem como professores e estudantes de graduação - bolsistas do PETNUT, e de pós-graduação em Nutrição da UFBA, integrantes do NEPAC, envolvendo ainda os pais e responsáveis dos alunos.

A primeira fase deste subprojeto foi a negociação com a escola, que ocorreu em julho de 2012, na perspectiva de uma construção coletiva. A proposta foi discutida inicialmente com a gestora da instituição de ensino, em seguida com o corpo docente, pais dos alunos e os próprios escolares. A construção da proposta, culminada na convergência entre a pesquisa de intervenção e a elaboração de um projeto interdisciplinar que iniciou na escola no segundo semestre de 2012, intitulado: "Aprender a ser conhecendo-se melhor para interagir melhor com o mundo".

A feira livre do bairro foi eleita como tema gerador para proporcionar a inserção do tema alimentação e nutrição no currículo escolar de forma interdisciplinar a ser trabalhado ao mesmo tempo nas disciplinas e em subprojetos conjuntos. A escolha do tema, partindo da perspectiva da feirinha, aludida anteriormente, foi justificada pelo grupo pela importância econômica e cultural que a feira livre tem para o bairro, assim como pela participação dos alunos no cotidiano da feira, seja como transeuntes ou consumidores dos seus produtos ou por ter pais trabalhando como feirantes.

Ademais, a feira livre é um espaço no qual o tema da alimentação en se configura de uma maneira interdisciplinar, proporcionando a discussão desde a produção até a comercialização dos alimentos, a questão da comensalidade bem como a construção da identidade alimentar e do bairro no qual a escola está inserida. Deste modo, o entrelace dos temas feira livre, com alimentação e nutrição, aprender a ser, aprender a comer e alimentação saudável foram centrais na construção do universo temático a ser trabalhado.

Em acordo com a direção e a coordenação pedagógica da escola a experiência foi realizada com estudantes do 8 으 e 9으 anos do ensino fundamental que compreende alunos da faixa etária de 12 a 15 anos. Elegeu-se esta faixa etária por considerar a possível facilidade de compreensão da realidade e o relativo grau de autonomia no que se refere às decisões que envolvem as práticas alimentares.

A implementação do projeto compreendeu a 4ㅇ unidade escolar ocorrida durante os meses de outubro e novembro de 2012. Os professores que se voluntariaram a participar do projeto foram os das seguintes disciplinas: no $8^{\circ}$ ano, Português, Francês, Ciências e Geografia; no 9oa ano, Ciências, Inglês e Cultura Baiana. Cada professor contou com o apoio de um ou dois graduandos do PETNUT que exerciam, ao mesmo tempo, a figura de monitor que contribuíam através do acompanhamento em sala de aula, da indicação de textos, do planejamento em conjunto de tarefas e/ou prestação de apoio técnico para melhor subsidiar a construção da relação do tema alimentação e nutrição com a disciplina em questão; - e de pesquisador, desenvolvendo durante o estudo a observação participante com produções de diários de campo. Esses graduandos foram acompanhados por nutricionistas mestrandas que fazem parte do NEPAC, as quais exerciam a função de tutoras, sendo estas responsáveis pela coordenação dos trabalhos e mediação da interação entre monitores e professores.

Os alunos do PETNUT construíram suas sugestões de ações educativas, para a associação do tema alimentação e nutrição (tomando a feira como objeto central) com os conteúdos disciplinares, a partir de discussões com professores e tutores, apoiados nos Marcos de Aprendizagem propostos pela Secretaria Municipal de Educação e adotados na escola para cada uma das disciplinas, nos Parâmetros Curriculares Nacionais (PCNs) correspondentes as disciplinas nas séries trabalhadas e no referencial teórico referente à alimentação, nutrição e temáticas correlatas. Os Marcos de Aprendizagem são documentos específicos para cada disciplina que descrevem para cada ano letivo as habilidades, conteúdos e eixos temáticos a serem trabalhados. 
Em paralelo, a equipe NEPAC em parceria com os professores da Escola Municipal desenvolveram atividades em momentos específicos, sendo eles: a elaboração de três provas da gincana e uma oficina fotográfica, com posterior exposição dos registros fotográficos na escola para os demais estudantes, pais, docentes e outros funcionários.

Nas provas da gincana o tema da feira livre foi inserido em três provas: em uma os alunos deveriam buscar histórias dos feirantes mais antigos da feira do bairro; na outra, a equipe que trouxesse a maior quantidade e variedade de frutas para o preparo de uma salada de frutas seria vencedora da prova; e a terceira, as equipes deveriam fazer uma exposição de artes com reciclagem de materiais utilizados na feira, utilizando o máximo de seu potencial criativo e artístico.

Essas provas tiveram como objetivo trabalhar mais uma forma de incentivo à aproximação e novas formas de lidar com a feira pelos alunos, com os seus produtos, além de contribuir com a visão crítica sobre aspectos ecológicos e de sustentabilidade, essenciais para a vida humana atual e futura. Essa foi uma das atividades que traduziu o encontro do Projeto Dia de Feira e do Aprender a Ser, por promover, ainda, o (re)conhecimento de aspectos históricos do bairro, a partir de sua feira livre.

Quanto à oficina de fotografias, esta foi desenvolvida com a equipe do PETNUT, trabalhando em parceria com a equipe do PET-Comunicação, com o objetivo de sensibilizar o olhar dos alunos da escola sobre a feira, através da linguagem iconográfica bem como aprender algumas técnicas e recursos fotográficos. O exercício prático da oficina foi constituído por equipes que focaram no registro fotográfico de temas diferentes sobre a feira, sendo eles: carnes e grãos; lixo e, por fim, frutas e verduras. A culminância foi uma exposição para a comunidade escolar, com participação dos alunos de outras séries, de pais e responsáveis dos alunos, bem como de funcionários da escola (participantes ou não do Projeto Dia de Feira). A atividade teve como objetivo despertar nos alunos um novo olhar sobre a realidade local através dos registros da feira livre do bairro, buscando com isso atribuir novos valores ao que é próprio do local, de sua economia e de sua cultura, como ainda estimular a criatividade necessária para a resolução de problemas.
Cabe destacar que, durante o desenvolvimento do Projeto Dia de Feira, diversos desafios imprimiram a necessidade de reduzir parte das atividades planejadas, entre eles, aspectos referentes desde a estrutura física da escola e aspectos administrativos (substituição e saída de professores), somados ao próprio desafio do trabalho interdisciplinar. Ao final da 40 unidade letiva, fez-se sua avaliação, com docentes e discentes da Escola Municipal participante do Projeto Dia de Feira. Com os primeiros utilizaram-se entrevistas semiestruturadas e com estudantes utilizaram-se grupos focais para a realização dessa avaliação, bem como a escrita de redações a respeito.

Em uma análise ainda em andamento, na perspectiva dos docentes da escola, a experiência foi considerada positiva por proporcionar uma contextualização maior da aprendizagem ao utilizar a feira como tema central. Valorizaram-se as vivências do bairro e dos alunos, o que pôde de alguma maneira, contribuir para a aprendizagem significativa dos alunos tanto sobre a temática do projeto quanto aos conteúdos das disciplinas. Destacou-se também a relevância do tema alimentação e nutrição como tema curricular/pedagógico e do projeto Dia de Feira, por oportunizar a formação crítica dos estudantes quanto ao consumo de alimentos, os interesses mercadológicos que estes possuem e o impacto destes sobre o biológico para a população infanto-juvenil.

Por outro lado, os docentes sinalizaram as dificuldades de construção de um projeto desta natureza, particularmente em estabelecer a relação entre os conteúdos a serem trabalhados nas disciplinas e a temática do projeto, em uma perspectiva interdisciplinar e transversal. Uma das dificuldades pontuadas foi o estabelecimento do diálogo entre os professores no planejar, executar e avaliar as disciplinas que tradicionalmente são trabalhadas de forma compartimentada.

$\mathrm{Na}$ perspectiva dos estudantes, os mesmos identificaram que houve um aumento de interesse pelas aulas, evidenciado pela maior frequência e participação dos alunos, assim como um melhor desempenho nas avaliações da unidade. Destacaram também uma ampliação do diálogo tanto entre os alunos como entre estes e os professores, na medida em que novas abordagens metodológicas foram utilizadas, a partir do trabalho em grupo. Ademais, a relação teoria e prática também mereceu destaque, uma vez que as aulas foram contextualizadas no universo da feira, ampliando 
atividades práticas - culinárias, visitas dirigidas à feira, dentre outras, proporcionaram um maior sentimento de pertencimento e fortalecimento das identidades locais a partir do tema. Um novo olhar sobre a feira foi construído partindo de um lugar sujo e desorganizado para um lugar de sociabilidades.

Todas as atividades desenvolvidas ao longo do Projeto Dia de Feira foram mediadas pela equipe NEPAC e PETNUT junto aos professores das disciplinas com o intuito de mobilizar os distintos saberes que envolvem e se relacionam com o campo da alimentação e nutrição. Houve, assim, um conjunto de protagonistas cuja ação pedagógica foi compartilhada, se constituindo em uma produção coletiva de conhecimentos.

\section{CONSIDERAÇÕES FINAIS}

Primeiramente, cabe salientar que o trabalho está em curso, mediante o desenvolvimento do projeto "Conversando sobre Comida", com os ACS como forma de continuidade à formação em alimentação e nutrição, e a continuidade do Projeto Dia de Feira, com a comunidade escolar. Em curso também está a análise do material empírico produzido ao longo do projeto, registrados em diários de campo e gravações do áudio de entrevistas semiestruturadas e grupos focais, como ainda das próprias oficinas da equipe.

As considerações finais sobre este processo serão focadas em três dimensões, das múltiplas a que este projeto se propôs a estudar, englobando aquelas que surgiram em campo: o desafio dos estudos sobre alimentação e nutrição e EAN, sob a ótica da SAN e DHAA.

Defende-se que tais experiências em que o confronto com a realidade social se constitui em um dos meios mais significativos de enfrentamento das dicotomias instituídas por meio da perspectiva epistemológica da ciência hegemônica, tais como na figuração de sujeitos e objetos, saberes acadêmicocientíficos/saberes populares - e outros saberes. A realidade concreta vista com novos olhares que evidenciam a sua complexidade, desafia os saberes disciplinares impondo, assim, a construção de novas práticas sustentadas por outros referenciais teóricos.

A EAN aqui trabalhada, inspirada no pensamento freiriano, pauta-se em uma perspectiva abrangente para além de ensinar a comer corretamente, vinculando-se mais ao pensar corretamente sobre o comer e o nutrir, como elemento fundante do processo de empoderamento dos sujeitos, apropriando-se de saberes que possibilitem fazer escolhas. Pensar corretamente o comer envolve também compreender o contexto em que se dá o ato de comer dos sujeitos. Assim, a dimensão do direito à alimentação envolvendo todo o processo desde a produção até o consumo dos alimentos, incorporando temas emergentes como sócio-sustentabilidade ambiental e a preservação das culturas alimentares tradicionais, exige uma constante reflexão das ciências da nutrição, enquanto um constructo sociocultural.

Vale ainda ressaltar que tais temas emergentes devem estar presentes no ato educativo não como "capítulos", mas aproveitando a capacidade interdisciplinar e transversal do tema da alimentação e nutrição. Tal premissa também reforça contrapor uma tendência a negligenciar o saber biomédico, as especificidades das patologias e a relação com os aspectos médico-nutricionais, como se a compreensão da determinação do hábito alimentar e a dimensão cultural fosse o suficiente. A interação entre os saberes biomédicos e os saberes socioculturais é um desafio urgente para o campo.

Nesta perspectiva, as experiências educativas buscaram construir conceitos e práticas alimentares mais pertinentes à realidade e experiência do grupo social e que, ao mesmo tempo, promovesse a interação entre as dimensões globais e locais, entre a promoção da alimentação saudável e preservação das culturas alimentares locais.

Além disso, um questionamento que parece caro para a área de educação e, talvez, mais ainda para o campo da saúde: como dar conta de apreender as experiências e vivências dos sujeitos, em particular, nos seus processos de aprendizagem em torno da alimentação e nutrição? Ou seja, como dimensionar a aprendizagem? Como construir indicadores pertinentes ao campo que envolvem a educação, para além de mensurar as mudanças comportamentais?

Por fim, assinala-se que, ao tomar o ato de comer como um objeto de reflexão, o processo educativo centrado nas experiências alimentares dos sujeitos impõe estratégias que são pautadas na superação das dicotomias biológico x social, natureza x cultura, individual x coletivo, ciências sociais e humanas $\mathrm{x}$ ciências da saúde, no confronto com a realidade 
concreta em que se conforma a relação dos sujeitos com o comer e a comida.

\section{AGRADECIMENTOS}

À Fundação de Amparo à Pesquisa do Estado da Bahia (FAPESB) pelo financiamento deste Projeto, ao Programa de Educação Tutorial do Ministério de Educação (PET-MEC) pelo financiamento dos bolsistas que trabalharam no projeto e às comunidades trabalhadas na cidade de Salvador-Bahia.

\section{REFERÊNCIAS}

[1] Costa CA, Bógus CM. Significados e apropriações da noção de Segurança Alimentar e Nutricional pelo segmento da sociedade civil do Conselho Nacional de Segurança Alimentar e Nutricional. Saúde Soc. 2012;21(1):103-114.

[2] Boog MCF. Educação nutricional: passado, presente, futuro. Rev Nutr. 1997;10(1):5-19.

[3] Valente F. Em busca de uma educação nutricional crítica. In: Valente F. Fome e desnutrição: determinantes sociais. São Paulo: Cortez; 1986.

[4] Lima ES, et al. Educação nutricional: da ignorância alimentar à representação social na pós-graduação do Rio de Janeiro, 1980-1998. Hist Ciênc Saúde Manguinhos. 2003;10(2):602-635.

[5] Santos LAS. Educação alimentar e nutricional no contexto da promoção de práticas alimentares saudáveis. Rev Nutr. 2005;18(5):681-92.

[6] Brasil. Ministério da Saúde. Secretaria de Atenção à Saúde. Departamento de Atenção Básica. Política Nacional de Alimentação e Nutrição. Brasilia, DF: MS; 2012 [acesso em 5 jun 2013]. Disponível em: http://dab.saude.gov.br/portaldab/pnan.php

[7] Instituto da Cidadania. Projeto Fome Zero: uma proposta de política de segurança alimentar para o Brasil. São Paulo; 2001.

[8] Brasil. Política Nacional de Promoção da Saúde. Ministério da Saúde, Secretaria de Vigilância em Saúde, Secretaria de Atenção à Saúde. 3. ed. Brasilia, DF: MS; 2010 [acesso em 22 abril 2012]. Disponível em: http://bvsms.saude.gov.br/bvs/publicacoes/politica nacion al promocao saude 3 ed.pdf

[9] Brasil. Ministério da Saúde, Secretaria de Atenção à Saúde, Departamento de Atenção básica, Coordenação-Geral da
Política de Alimentação e Nutrição. Guia Alimentar para a população brasileira: Promovendo a Alimentação Saudável. Série A. Normas e Manuais Técnicos, Brasília - DF, 2006.

[10] Brasil. Ministério do Desenvolvimento Social e Combate à Fome. Marco de referência de educação alimentar e nutricional para as políticas públicas. Brasília, DF: MDS; 2012 [acesso 2013 jun5]. Disponível em: http://www.ideiasnamesa.unb.br/files/marco EAN visuali zacao.pdf

[11] AlzateYT. Desde laeducación para lasalud: hacialapedagogía de laeducación alimentaria y nutricional. Perspect Nutr Hum. 2006;16:21-40.

[12] Instituto de Tecnologia Social (ITS). Caderno Tecnologia Social - Conhecimento e Cidadania, 2007. № 01 [acesso em 8 maio 2012]. Disponível em: http://www.itsbrasil.org.br

[13] Rodrigues I, Barbieri JC. A emergência da tecnologia social: revisitando o movimento da tecnologia apropriada como estratégia de desenvolvimento sustentável. Rev Adm Pública. 2008;42(6):1069-94.

[14] Lassance Jr AE, Pedreira JS. Tecnologias sociais e políticas públicas. In: Lassance Jr AE, et al. Tecnologia social: uma estratégia para o desenvolvimento. Fundação Banco do Brasil - Rio de Janeiro: 2004.

[15] Bonilha MC, Sachuk MI. Identidade e tecnologia social: um estudo junto às artesãs da Vila Rural Esperança. Cadernos EbapeBr. 2011:9(2):412-437.

[16] Santos LAS. O fazer Educação Alimentar e Nutricional: algumas contribuições para reflexão. Ciênc Saúde Coletiva. 2012;17(2):455-62.

[17] Brasil. Lei № 11.346, de 15 de setembro de 2006. Cria o Sistema Nacional de Segurança Alimentar e Nutricional SISAN com vistas em assegurar o direito humano à alimentação adequada e dá outras providências. Presidência da República - Brasília, 15 de setembro de 2006; 185o da Independência e 118o da República [acesso em 21 abril 2012]. Disponível em: http://www4.planalto.gov.br/consea/legislacao/decretonb0-7-272-de-25-de-agosto-de-2010/view

[18] Brasil. Resolução FNDE/CD № 38 de 16 de julho de 2009. Dispõe sobre o atendimento da alimentação escolar aos alunos da educação básica no Programa Nacional de Alimentação Escolar - PNAE. Brasilia, DF: MEC, 2009.

[19] Soares MD. Práticas de cuidado alimentar de crianças e sentidos atribuídos aos discursos sobre alimentação e 
nutrição por cuidadores domiciliares. [Tese] Salvador: UFBA; 2011. 256 p.

[20] Amparo-Santos L. Avanços e desdobramentos do marco de referência da educação alimentar e nutricional para políticas públicas no âmbito da universidade e para os aspectos culturais da alimentação. Rev Nutr. 2013:26(5):595600 .

[21] Azevedo E. Reflexões sobre riscos e o papel da ciência na construção do conceito de alimentação saudável. Rev Nutr. 2008: 21(6):717-723

[22] Brandão CR. O que é método Paulo Freire. São Paulo: Brasiliense, 1981.

[23] Moreira MA. Aprendizagem significativa. Brasília: Editora Universidade de Brasília; 1999.
[24] Fávero MH. A pesquisa de intervenção na psicologia da educação matemática: aspectos conceituais e metodológicos. Educar em Revista. 2011;1:47-62.

[25] Geertz C. Uma descrição densa: por uma teoria interpretativa da cultura. In: —. A interpretação das culturas. Rio de Janeiro: LTC, 1989. p. 3-21.

[26] Minayo MCS, Assis SG, Souza ER. (Org). Avaliação por Triangulação de Métodos: Abordagem de Programas Sociais. Rio de Janeiro: Editora Fiocruz; 2005. 244 p.

[27] Martins JB. Contribuições epistemológicas da abordagem multirreferencial para a compreensão dos fenômenos educacionais. Rev Bras Educ. 2004;26:85-94.

[28] Freire P. Pedagogia do Oprimido. Rio de Janeiro: Ed. Paz e Terra, 1975. 